\title{
Dietary Induction of Intestinal Fructose Absorption in Weaning Rats
}

\author{
ELMER S. DAVID, DAVID S. CINGARI, AND RONALDO P. FERRARIS \\ Departments of Pediatrics [E.S.D.] and Physiology [R.P.F.], University of Medicine and Dentistry of New \\ Jersey, New Jersey Medical School, Newark, New Jersey 07103-2714
}

\begin{abstract}
The onset of developmentally induced changes in rat intestinal nutrient absorption is well known: brushborder glucose and fructose transporters appear during prenatal and postweaning periods, respectively. The onset of diet-induced regulation, however, is unknown. To test the hypothesis that intestinal glucose and fructose transport is regulated by diet during weaning and postweaning, we fed rats experimental diets containing high $(65 \%)$ glucose, high fructose, high sucrose, or no carbohydrate. In 16-d-old rats, $6 \mathrm{~d}$ of dietary fructose but not glucose modestly increased fructose absorption in everted sleeves of small intestine (SI) over control (mother-fed with access to chow) rats ( $p=$ 0.02 ). In 21-d-old (age when sucrase is present) rats, dietary fructose and sucrose each dramatically enhanced $(p=0.004)$ fructose absorption over control rats and rats fed high glucose or carbohydrate-free diets. In 35- (postweaning) and 60-d-old rats, dietary fructose and sucrose, but not glucose, stimulated fructose absorption $(p<0.005)$ over rats fed a carbohydrate-free diet. In all age groups, intestinal glucose absorption was independent of
\end{abstract}

diet ( $p \geq 0.12$ ), and experimental rats grew at the same rate as control rats. Absorption of fructose or glucose was 2-3 times greater in the proximal and middle than in the distal SI. Intestinal fructose, but not glucose, absorption can be induced by diet even during early weaning, and dietary fructose followed by sucrose is the most potent inducer. Thus, mechanisms of diet regulation can change ontogenetically, and early introduction of certain diets can induce appearance of certain nutrient transporters. (Pediatr Res 37: 777-782, 1995)
ANOVA, analysis of variance
Abbreviations
HF, high fructose
HG, high glucose
HS, high sucrose
MMC, mother-fed/chow
NC, no carbohydrate
SI, small intestine

Advances in infant nutritional support have increased premature infant survival, especially in the low birth weight neonates (1). Premature neonates are typically fed simple sugars and even infant formula not only to prime their gut but also to provide an enteral source of nutrition. Approximately $40 \%$ of the energy intake of all infants is provided by carbohydrates (2), mainly glucose, galactose, and even fructose, and the neonatal small intestine encounters them mainly as breakdown products of carbohydrate digestion. Intestinal glucose transport appears prenatally, at around the 24th wk of gestation in humans (3) and just before birth in rats $(4,5)$. The onset of intestinal fructose transport in rats, on the other hand, is postnatal (5). There is an enhancement of fructose transport at the end of weaning in rats, and this happens despite the absence

Received August 25, 1994; accepted January 3, 1995.

Correspondence: R. P. Ferraris, Ph.D., Department of Physiology, University of Medicine and Dentistry of New Jersey, New Jersey Medical School, 185 S. Orange Ave., Newark, NJ 07103-2714.

Supported by National Institutes of Health grant AG11403, by the Department of Commerce (Sea Grant NA36-RG0505 (R/F-58)), and by the American Federation for Aging Research (to R.P.F.).

D.S.C.'s summer fellowship was sponsored by the Foundation of UMDNJ. of fructose in the diet (6). This ontogenetic milestone requires no dietary cues and is an endogenous phenomenon that seems to prepare rats to dietary adaptation.

In adults, certain intestinal nutrient transporters such as that of glucose and fructose are adaptively and reversibly regulated by the dietary levels of their substrates (7-9). In the case of the neonatal animal where there is an inherent problem of distinguishing between diet-induced, reversible changes from ontogenetic, often irreversible influences, the paucity of published data on development of dietary regulation prevents us from making the same statement. In bullfrogs which develop from herbivorous/omnivorous tadpoles to carnivorous adults, Toloza and Diamond (10) were able to distinguish between development of transport processes from development of rapid, reversible dietary regulation itself, and they observed that regulatory capacity found in tadpoles becomes lost in adults.

In this study, dietary induction and regulation of small intestinal fructose and glucose transport were investigated in weaning and postweaning rats. Inasmuch as glucose is present in a rat's diet throughout its lifetime and fructose does not appear in the diet until after weaning when the rat starts to 
consume chow, these two sugars will enable us to compare two different patterns of transporter development or regulation. We found that fructose transport can apparently be induced and regulated by diet throughout weaning and postweaning in rats; in contrast, we found no dietary regulation of glucose transport in every neonatal age group studied.

\section{MATERIALS AND METHODS}

Animals. Pregnant Sprague-Dawley rats (Charles River Laboratories, Wilmington, MA) were purchased on the 19th day of gestation and caged separately with constantly available water and chow. Litters were born at 21-23 d of gestation and stayed with dams (except 60-d-old rats) until entry into the study. Pups of either sex aged 16 (early weaning), 21 (late weaning), 35, and 60 (postweaning) d were weighed and randomly assigned to their respective diet groups.

Each group was kept on experimental diets for 6-7 d, then killed. Six days provide ample time for complete adaptation to dietary carbohydrate (11). In experiment 1 , there were three groups of 16-d-old, early weaning rats: those fed a $\mathrm{HG}$ diet, those fed a HF diet, or those control rats (MMC) which stayed with the mother and had access to both mother's milk and chow (Purina Lab Rodent Chow, Purina Mills, Richmond, IN). In experiment 2 , there were five groups of 22 -d-old, late weaning rats: control (MMC) and those fed $\mathrm{HG}, \mathrm{HF}$, and two additional diets, HS and NC. The HS was introduced to this and older groups because intestinal enzyme sucrase activity is about $40 \%$ developed at $22 \mathrm{~d}(12)$; the $\mathrm{NC}$ diet because 16-d-old pups do not eat NC pellets. Rats in experiments 1 and 2 were killed at age 22 and $28 \mathrm{~d}$, respectively. In experiments 3 and 4, 35- and 60-d-old postweaning rats were fed $\mathrm{HG}, \mathrm{HF}$, $\mathrm{HS}$, or NC diets and were killed at age 42 and $67 \mathrm{~d}$, respectively. The NC rats in experiments 3 and 4 served as controls. Each pup in each age group was provided a cage except for 16-d-old pups belonging to the same diet group. The 16-d-old pups were caged together to maintain body warmth. For 1622- and 21-28-d-old pups, body weights and food weights were each determined in the beginning, middle, and at the end of each experiment. For 35-42- and 60-67-d-old pups, body and food weights were determined in the beginning and end of each experiment. Feeding rate was determined by subtracting the weight of food remaining in the food bin from the initial amount, and the difference was divided by the number of days.

Diets. The HG, HF, HS (Dyets Inc., Bethlehem, PA), and $\mathrm{NC}$ (ICN, Cleveland, $\mathrm{OH}$ ) diets were supplied in pelletized form. The $\mathrm{HG}, \mathrm{HF}$, and $\mathrm{HS}$ diets each consisted of $65 \%$ glucose, fructose, and sucrose, respectively, and $20 \%$ casein. Diets were otherwise isocaloric to each other (other components are: $5 \%$ corn oil, $5 \%$ cellulose, $3.5 \%$ salt mix, $1 \%$ vitamin mix, $0.3 \%$ DL-methionine, and $0.2 \%$ choline bitartrate).

In preliminary experiments, we could not come up with an ideal isocaloric NC diet containing only casein and other components at levels identical to other diets, yet at the same time would maintain weight and would be consumed at rates similar to the sugar-containing diets. For this study, we had to settle for a NC diet frequently used in our laboratory $(13,14)$ and in other laboratories (15), a diet that differed slightly in some dietary components yet supported or maintained body weights and resulted only in modest decreases in feeding rates. The NC diet had $0 \%$ carbohydrate and $70 \%$ protein. The other components were $7 \%$ vegetable oil, $16 \%$ cellulose, $1 \%$ vitamin mix, $4 \%$ mineral mix, and $2 \%$ brewer's yeast. These minor differences in diet composition and modest decreases in feeding rates turned out to be negligible, because a low carbohydrate diet with exactly the same composition (except for carbohydrate and protein levels) as those of the sugarcontaining diets resulted in uptakes that were statistically similar to the NC diet (David ES, Ferraris RP, unpublished data).

Uptake measurements. Glucose and fructose uptake rates into the small intestinal mucosa were determined by using the everted sleeves technique described in detail elsewhere (16). Experiments were carried out mid-day between 1000 and 1400 $\mathrm{h}$ to minimize the effect of diurnal rhythm. Rats were not starved before death. After anesthesia and death with pentobarbital injection (i.p., $0.1 \mathrm{~mL} / 30 \mathrm{~g}$ body weight), the SI was isolated, gently flushed with ice-cold Ringer's solution (composition: $\mathrm{NaCl}, 128 \mathrm{mmol} / \mathrm{L} ; \mathrm{KCl}, 4.7 ; \mathrm{CaCl}_{2}, 2.5 ; \mathrm{KH}_{2} \mathrm{PO}_{4}$, $1.2 ; \mathrm{MgSO}_{4}, 1.2$; and $\mathrm{NaHCO}_{3}, 20 ; \mathrm{pH}$ 7.3-7.4; osmolarity, $290 \mathrm{mosmol} / \mathrm{kg}$ ), then subdivided into three regions: proximal (20\% of SI length distal to pylorus), distal (20\% of SI length proximal to cecum), and middle $60 \%$. Total intestinal length was determined from pyloric sphincter to ileocecal junction. The mid-segment from each region was everted on a glass rod and two 1-cm sleeves were obtained from each.

Each sleeve was mounted on a grooved glass rod (3-mm diameter), preincubated for $5 \mathrm{~min}$ in $37^{\circ} \mathrm{C}$ mammalian Ringer's solution bubbled with $95 \% \mathrm{O}_{2}-5 \% \mathrm{CO}_{2}$, then incubated at $37^{\circ} \mathrm{C}$ in the oxygenated solution containing the test tracer for glucose, $\mathrm{D}-\left[{ }^{14} \mathrm{C}\right]$ glucose, for $1 \mathrm{~min}$ or fructose, $\mathrm{D}-\left[{ }^{14} \mathrm{C}\right]$ fructose, for $2 \mathrm{~min}$. A 20 -s rinse in $30 \mathrm{~mL}$ ice-cold Ringer's solution was then done to reduce the radioactive label in the adherent fluid. $\mathrm{L}-\left[{ }^{3} \mathrm{H}\right]$ Glucose was used to correct simultaneously for adherent fluid and for D-glucose or $\mathrm{D}$-fructose passive uptake by diffusion thereby yielding carrier-mediated sugar uptake. All radioisotopes were purchased from DuPont NEN (Boston, MA). The uptake rates of both D-glucose and D-fructose were determined at $50 \mathrm{mM}$ because this is the concentration that yields the $V_{\text {max }}$, and $V_{\max }$ determinations are not affected by errors caused by unstirred layers (16).

Uptakes were determined in each of three regions. There were four to seven pups per diet per age group and each experiment was conducted in two to three batches. Results were expressed as nanomoles per mg wet weight of SI.

Statistical analysis. Results are presented as means \pm SEM. A one-way ANOVA was used to analyze in each age group, diet effects on body weight, feeding rates, intestinal weight, and intestinal length. The simultaneous effects of diet and intestinal position on glucose and fructose uptake were analyzed by two-way ANOVA. Two-way ANOVA was also used to test for simultaneous effects of diet and experimental duration on body weight and on feeding rate. A level of $p=0.05$ or less was considered statistically significant. Statistical analysis was conducted using the STATGRAPHICS Program (Statistical Graphics Corp., Princeton, NJ). 


\section{RESULTS}

\section{Body Weight}

Two-way ANOVA revealed a highly significant effect of experimental time ( $p<0.0001$, Fig. $1 A)$ but no effect of diet $(p>0.4)$ on body weight. All 16-22-d-old pups gained weight after a 6-d exposure to experimental diets. The average weight across diets is $32.6 \pm 0.8(n=19), 36.2 \pm 1.2(n=19)$, and $53.3 \pm 1.7(n=19) \mathrm{g}$ at the beginning, in the middle and at the end of the experiment, respectively.

There was a highly significant effect of diet $(p<0.0001$, Fig. $1 B)$ and experimental time $(p<0.0001)$ on body weight of 21-28-d-old pups. Although initial body weight was the same $(p=0.4)$ and all rats grew on each experimental diet, one-way ANOVA showed that there was already a modest diet-induced difference in body weight by $24 \mathrm{~d}(p=0.02)$ and a significant difference in body weight by the end of experiment at $28 \mathrm{~d}$ of age $(p=0.002)$.

There was no effect $(p=0.26$, Fig. $1 C)$ of diet nor of experimental time ( $p=0.13)$ on body weight of 35-42-d-old rats. The average weight across experimental time is $161 \pm 5$ $(n=12), 162 \pm 7(n=12), 174 \pm 5(n=12)$, and $174 \pm 6$ $(n=12) \mathrm{g}$ for HG, HF, HS, and NC rats, respectively. The

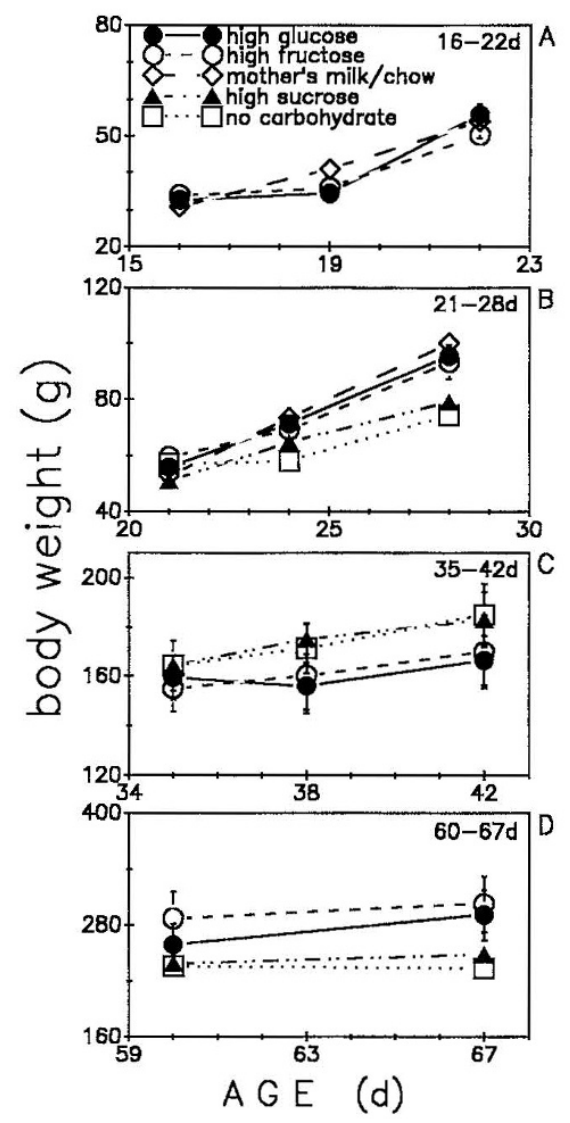

Figure 1. Body weights of weaning and postweaning rats fed various experimental diets. $A$, 16-d-old pups were fed for $6 \mathrm{~d}$ a $\mathrm{HG}(n=7), \mathrm{HF}(n=7)$, or control diet (MMC, $n=5$ ). $B, 21$-d-old pups were fed for $7 \mathrm{~d}$ a $\mathrm{HG}, \mathrm{HF}, \mathrm{HS}$, $\mathrm{NC}$, or MMC diet $(n=6$ except for MMC, where $n=4)$. $C, 35$-d-old rats were fed for $7 \mathrm{~d}$ a HG, HF, HS, or NC diet ( $n=4$ per diet group). $D, 60$-d-old rats were fed for $7 \mathrm{~d}$ a HG, HF, HS, or NC diet $(n=4)$. Please see text for statistical comparisons. mean body weight regardless of diet was $161 \pm 4(n=16)$, $166 \pm 5(n=16)$ and $176 \pm 6(n=16) \mathrm{g}$ in the beginning, middle and end of the experiment, respectively.

There was a modest effect of $\operatorname{diet}(p=0.03$, Fig. $1 D)$ but no effect of experimental time $(p=0.36)$ on body weight of 60-67-d-old rats. The average weight across experimental time for each diet is $275 \pm 17 \mathrm{~g}(n=8), 290 \pm 20 \mathrm{~g}(n=8)$, $244 \pm 7 \mathrm{~g}(n=8)$, and $235 \pm 6 \mathrm{~g}(n=8)$ for $\mathrm{HG}, \mathrm{HF}, \mathrm{HS}$, and $\mathrm{NC}$ rats, respectively.

\section{Feeding Rate}

Because weaning (ages 16-22 d and 21-28 d) rats were growing rapidly, feeding rates were determined in two time intervals: on $\mathrm{d} 3$ (representing the average initial feeding rate between experimental $\mathrm{d} 1$ and 3 ) and on $\mathrm{d} 6$ (representing the final feeding rate between experimental $\mathrm{d} 4$ and 6 ). The feeding rate of HG-fed, 16-22-d-old pups was 2.8 (initial) and 8.8 $\mathrm{g} / \mathrm{d} / \mathrm{rat}$ (final), whereas that of HF-fed pups was 1.9 (initial) and $6.4 \mathrm{~g} / \mathrm{d} / \mathrm{rat}$ (final). We have no standard errors nor statistical analysis for the feeding rate of 16-22-d-old pups because these were collectively caged into diet groups for body warmth.

In 21-28-d-old pups, there was a highly significant effect of $\operatorname{diet}(p<0.0001$ by two-way ANOVA) and of experimental time $(p<0.0001)$ on feeding rate. As expected, rats in each experimental diet consumed more in the latter stages of the experiment. Compared with pups fed other diets, the NC-fed pups consumed the least amount of food from $\mathrm{d} 1-3$ [5.1 \pm 0.6 $\mathrm{g} / \mathrm{d} / \mathrm{rat}(n=6)(p<0.0001)]$ and from d 4-6 $[9.5 \pm 1.5$ $\mathrm{g} / \mathrm{d} / \mathrm{rat}(n=6)(p=0.007)]$. Feeding rate was not different among pups fed HG, HF, and HS diets. For these diets, the average food consumption was $9.0 \pm 1.5(n=18)$ for $\mathrm{d} 1-3$ and $12.7 \pm 1.8 \mathrm{~g} / \mathrm{d} / \mathrm{rat}(n=18)$ for $\mathrm{d} 4-6$.

There was no effect of diet on feeding rate of 35-42-d-old rats $(p=0.9)$. The average feeding rate in this age group across diets was $14.3 \pm 1.3 \mathrm{~g} / \mathrm{d} / \mathrm{rat}(n=16)$. In 60-67-d-old rats, the NC-fed rats consumed the least amount at $14.8 \pm 1.0$ $\mathrm{g} / \mathrm{d} / \mathrm{rat}(n=4, p=0.03)$. The average feeding rate of $\mathrm{HG}, \mathrm{HF}$, and HS-fed rats was $23.1 \pm 2.5 \mathrm{~g} / \mathrm{d} / \mathrm{rat}(n=12)$.

\section{Intestinal Weight and Length}

In 22-d-old pups, diet had a slight ( $p=0.02$ ) effect on small intestinal weight, but had no effect on length $(p=0.13)$. For HF-fed pups, mean intestinal weight was $3.31 \pm 0.18 \mathrm{~g}(n=$ 7 ); for HG pups, $3.92 \pm 0.16 \mathrm{~g}(n=7)$; and for MMC pups $4.45 \pm 0.44 \mathrm{~g}(n=5)$. The overall mean intestinal length for this age group across diets was $76.5 \pm 2.5 \mathrm{~cm}(n=19)$.

In 28-d-old pups, diet also had a modest effect on both intestinal length $(p=0.02)$ and intestinal weight $(p=0.02)$. Rats fed HG had a lesser intestinal length and weight (79.6 \pm $4.2 \mathrm{~cm}$ and $5.2 \pm 0.1 \mathrm{~g}$, respectively, $n=6$ ) compared with those of other rats. Intestinal lengths and weights were, respectively, $91.5 \pm 3.8 \mathrm{~cm}$ and $5.6 \pm 0.4 \mathrm{~g}$ in HF rats, $88.1 \pm 2.2$ $\mathrm{cm}$ and $5.7 \mathrm{~g} \pm 0.3$ in HS rats, $89.9 \pm 4.5 \mathrm{~cm}$ and $4.9 \pm 0.2 \mathrm{~g}$ in $\mathrm{NC}$ rats, and $101.8 \pm 3.2 \mathrm{~cm}$ and $6.5 \pm 0.4 \mathrm{~g}$ in MMC rats $(n=4-6)$.

Diet had a significant effect on intestinal weight $(p=0.01)$ but not on intestinal length $(p=0.23)$ in 42 -d-old rats. The 
average intestinal length regardless of diet in this age group was $117 \pm 3(n=16) \mathrm{cm}$. Intestinal weights were $6.2 \pm 0.2$, $7.2 \pm 0.4,7.8 \pm 0.3$, and $8.0 \pm 0.5 \mathrm{~g}(n=4$ for each diet $)$ for $\mathrm{HG}, \mathrm{HF}, \mathrm{HS}$, and $\mathrm{NC}$ rats, respectively.

In 67-d-old rats, intestinal weight $(p=0.16)$ and intestinal length $(p=0.27)$ were each independent of diet. Overall mean intestinal length and weight in this age group across diets were $126 \pm 3 \mathrm{~cm}(n=16)$ and $10.0 \pm 0.5 \mathrm{~g}(n=16)$, respectively.

\section{Sugar Uptake}

Fructose uptake. In 16-22-d-old pups, fructose uptake per mg SI varied strongly with both intestinal position ( $p=$ 0.0003 , Fig. $2 A)$ and diet $(p=0.0008)$. Dietary fructose stimulated fructose absorption per $\mathrm{mg}$ by 1.6 times (one-way ANOVA, $p=0.001$ ) in the proximal, by 1.4 times in the middle $(p=0.07)$, but not in the distal $(p=0.5)$ intestine. Intestinal position $(p<0.0001)$ and $\operatorname{diet}(p=0.0001)$ also had a similar effect on fructose uptake per $\mathrm{cm}$ SI (not shown). Dietary fructose enhanced fructose absorption per $\mathrm{cm}$ by $1.3-$ 1.5 times in the proximal and middle SI.

Two-way ANOVA showed a highly significant effect of diet $(p<0.0001)$ and intestinal position $(p<0.0001)$ on brushborder fructose absorption per mg in 21-28-d-old pups (Fig.

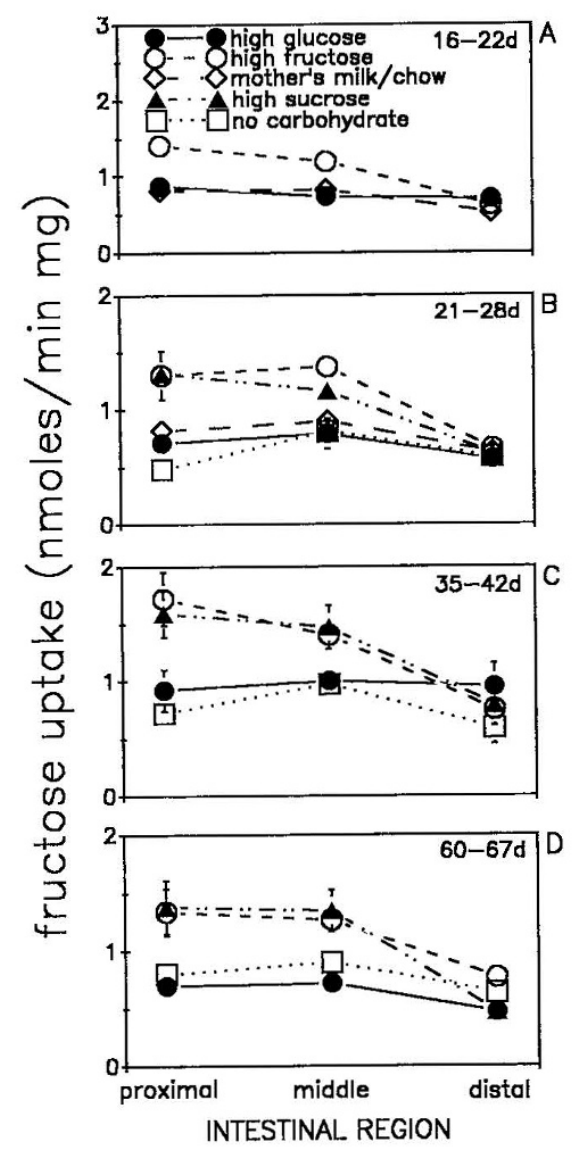

Figure 2. Brushborder fructose uptake by everted sleeves of proximal, middle, and distal SI of weaning and postweaning rats. Points are means \pm SEM ( $n=$ same as in Fig. 1). A, Dietary fructose enhanced fructose uptake in the proximal and middle SI of early weaning rats. $B, C$, and $D$, Dietary fructose and sucrose each significantly increased uptake in the proximal and middle SI of late weaning and postweaning rats.
$2 B$ ). Dietary fructose and sucrose each up-regulated fructose absorption per $\mathrm{mg}$ by $1.5-1.7$ times in both the proximal (one-way ANOVA, $p=0.0003)$ and middle $(p=0.0002)$ but not in the distal $(p=0.94)$ SI. Fructose uptake per $\mathrm{cm}$ SI is also significantly affected by diet $(p<0.0001)$ and intestinal position ( $p<0.0001$, data not shown). As expected, fructose absorption per $\mathrm{cm}$ was significantly greater in the HF- and HS-fed pups.

Two-way ANOVA indicated highly significant effects of $\operatorname{diet}(p=0.0008$, Fig. $2 C)$ and intestinal position $(p=0.001)$ on brushborder fructose absorption per mg SI in $35-42 \mathrm{~d}$ rats. Dietary fructose and sucrose each stimulated fructose absorption by about 2 times in the proximal (one-way ANOVA, $p=$ $0.005)$ and by 1.5 times in the middle $(p=0.04)$ but not in the distal $(p=0.16)$ SI. Fructose uptakes per $\mathrm{cm}$ also varied strongly with diet $(p<0.0001)$ and intestinal position $(p<$ 0.0001 , data not shown). Both HF and HS diets enhanced fructose absorption per $\mathrm{cm}$ by $2-3$ times in the proximal (one-way ANOVA, $p=0.0002)$ and middle $(p=0.0001)$ but not in the distal $(p=0.26)$ SI.

By two-way ANOVA, fructose absorption per mg SI varied strongly with diet $(p<0.0001$, Fig. $2 D)$ and intestinal position $(p<0.0001)$ in $60-67-d-o l d$ rats. Both HF and HS diets stimulated fructose absorption per $\mathrm{mg}$ in the proximal ( $p=$ $0.02)$, middle $(p=0.005)$, and in the distal $(p=0.03)$ SI. Fructose uptake per $\mathrm{cm}$ also varied strongly with diet $(p<$ $0.0001)$ and intestinal position ( $p<0.0001$, data not shown). Fructose absorption per $\mathrm{cm}$ was stimulated 2 times by HF and HS in the proximal ( $p=0.02$, one-way ANOVA), middle $(p=0.005)$ and distal $(p=0.03)$ SI.

In every age group studied, fructose uptakes per $\mathrm{mg}$ and per $\mathrm{cm}$ SI are significantly greater $(p<0.01)$ in the proximal and middle segments compared with the distal SI.

Glucose uptake. Two-way ANOVA showed that intestinal glucose uptake per $\mathrm{mg}$ varied with intestinal position in 16-22$(p<0.0001$, Fig. 3), 21-28- $(p<0.0001), 35-42-(p=$ $0.0004)$, and 60-67- $(p<0.0001) \mathrm{d}$-old rats but not with diet ( $p=0.50, p=0.12, p=0.75$, and $p=0.63$, respectively). Intestinal glucose uptake per $\mathrm{cm}$ also varied with intestinal position in 16-22- $(p<0.0001), 21-28-(p=0.0001), 35-42-$ $(p<0.0001)$, and 60-67- $(p<0.0001) \mathrm{d}$-old rats. There was also no effect of diet on glucose uptake per $\mathrm{cm}(16-22 \mathrm{~d}, p=$ $0.99 ; 35-42 \mathrm{~d}, p=0.4$, and $60-67 \mathrm{~d}, p=0.11$ ) except in the 21-28-d-old pups where diet had an effect $(p=0.0002)$. There was a 1.6-3 times higher glucose uptake per $\mathrm{mg}$ and per $\mathrm{cm}$ in the proximal and middle compared with the distal SI across all diets in every age group of rats studied $(p<0.01)$.

\section{DISCUSSION}

Two important findings are noted in this study: that dietary fructose induces SI fructose transport in weaning and postweaning rats and that dietary carbohydrate has no effect on intestinal glucose transport.

Precocious enhancement of intestinal fructose transport by diet. Fructose transport is nominal before and during weaning (6) and parallels the absence of dietary fructose in these developmental stages. Our results show that fructose transport 


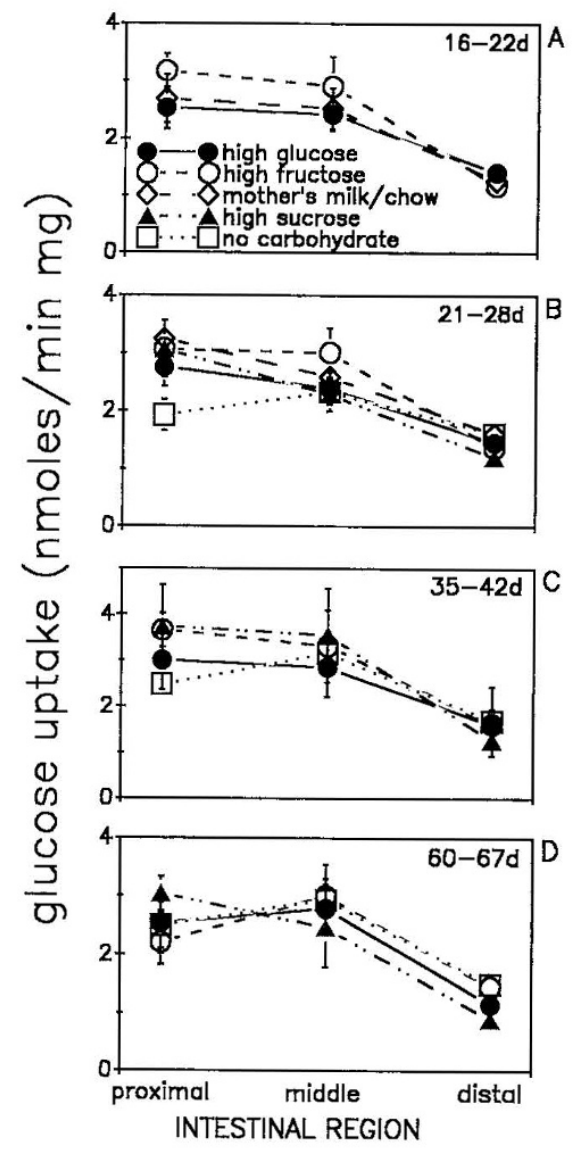

Figure 3. Brushborder glucose uptake by everted sleeves of rat proximal, middle and distal SI. Points are means $\pm \operatorname{SEM}(n=$ same as in Fig. 1). $A, B$, $C$, and $D$, No statistically significant differences in glucose uptake among diets in each age group. Regardless of diet and age group, glucose uptake was higher in the proximal and middle than in the distal SI.

can be induced even during early weaning and that this induction requires luminal fructose, either as a dietary constituent or as a breakdown product of the hydrolytic digestion of sucrose. Dietary enhancement of fructose transport seems to become more pronounced in later developmental stages. In adult rats, the brushborder fructose transporter, GLUT5, is rapidly upregulated by dietary fructose (17).

Because intestinal mass was independent or only modestly dependent on diet, stimulation of fructose transport in weaning and postweaning rats represents specific induction of fructose transporters, a finding similar to that seen in adult mice (18) and rats (17). In 16- and 21-d-old rats, this increase in fructose transport cannot be due to a precocious shift to a solid diet because intestinal fructose transport does not increase in NCand HG-fed rats. It also cannot be due to an internal, developmentally programmed increase in fructose transport by 21-dold mice killed at $28 \mathrm{~d}$, because fructose transport can be induced in younger (16-d-old) pups before the internal developmentally programmed increase is supposed to become activated, and because fructose absorption in 28-d-old HG- and $\mathrm{NC}$-fed pups remain low. Low values of fructose transport in 28-d-old MMC pups were surprising because these pups already had access to chow which contains fructose, but perhaps the levels of fructose in chow (5.5\% by dry weight) (6) are too low to induce fructose transport. This suggests that there may be a critical level of dietary fructose sufficient to induce fructose transport. Because cell turnover takes $22 \mathrm{~d}$ in the SI of weanling (17-d-old) rats as opposed to $2 \mathrm{~d}$ in adult rats (19), our results also suggest that fructose transport which can be induced overnight by a HF diet (David ES, Ferraris RP, unpublished observation) may be inducible in mature enterocytes already present in the villi of weaning rat SI, in contrast to that of glucose transport which is not inducible in mature villus enterocytes (11) as will be discussed below.

Dietary modulation of glucose transport is absent. In sharp contrast to fructose transport, glucose transport in weaning and postweaning rats is independent of diet. Although glucose transport rates are already high in neonatal rats, glucose transport cannot be regulated by diet until after $60 \mathrm{~d}$. Thus, not only is ontogenetic development of glucose transport itself different from that of fructose but development of rapid, reversible, dietary regulation of these two sugars is different as well. The explanation for this finding may be related to Ferraris and Diamond's (11) observation in adult mice that the dietary signal for $\mathrm{Na}^{+}$-dependent glucose transporter regulation is perceived only in undifferentiated crypt cells and that the observed lag in diet-induced change in uptake is due largely to cell migration times. If only crypt cells can mediate dietinduced changes in $\mathrm{Na}^{+}$-dependent glucose transport, then differences in intestinal cell migration times provide an important clue outlining differences in regulatory mechanisms of intestinal glucose transport mediated by SGLT1 (20) and fructose transport mediated by GLUT5 (17). Because cell migration rates are very low in neonatal rats (explaining the long cell turnover time), then the observed diet-induced changes in fructose transport must develop in differentiated, mature villus cells. Transport mediated by GLUT proteins are indeed known to be rapidly inducible (about $4 \mathrm{~h}$ in the basolateral membrane of rat intestinal cells) (21), partly by a combination of a modulation of carriers already in the membrane and subsequent changes in carrier site density (22). In contrast, the absence of any diet-induced change in $\mathrm{Na}^{+}$-dependent glucose transport in weaning rats indicate that changes in intestinal $\mathrm{Na}^{+}$. dependent glucose transport may have to be mediated by irreversible programming of $\mathrm{Na}^{+}$-dependent glucose transporters in immature enterocytes in the crypt; if cell turnover times are slow, rates of $\mathrm{Na}^{+}$-dependent glucose transport will not change as rapidly as those of fructose transport. The absence of dietary regulation of glucose transport in weaning rats may confer some advantage because glucose transport will always remain high even if glucose is withdrawn from the diet.

Unsolved problems and future studies. Adult rats are known to regulate intestinal glucose transport in response to changes in dietary carbohydrate $(23,24)$. Because we did not observe dietary regulation of glucose transport in 60-d-old rats, the onset of dietary regulation for glucose transport must take place after $60 \mathrm{~d}$ of age, which is past the age when rats encounter variable amounts of carbohydrate in the diet. We also did not observe a diet-independent, apparently internally programmed increase in intestinal fructose transport at $28 \mathrm{~d}$, perhaps because our protocol differs from that of Toloza and Diamond (6) who killed rats on a daily basis until the increase 
was clearly distinct from uptake rates of younger rats. Finally, we found dietary sucrose to induce fructose transport in weaning and postweaning rats but Burant et al. (17) who used adult rats could not induce expression of the fructose transporter with dietary sucrose. Further studies are needed to differentiate the regulatory effect of dietary fructose from that of fructose liberated from dietary sucrose.

The findings in these experiments have opened avenues of further study for us to pursue. First, what is the time course for induction of intestinal fructose transport? In rats, a 3-d exposure to fructose diet is sufficient to induce a 2-fold or greater increase in fructose uptake $(23,25)$. These studies used adults and the neonatal aspects have essentially been neglected. Second, how much dietary fructose is required for induction? Again, the adult studies previously quoted have used high concentrations of dietary fructose to show modulation. Third, is induction of fructose transport controlled at the transcriptional or at the translational level? We have alluded earlier to the point that fructose transport induction may represent specific induction of fructose transporters. Likewise, it is not known whether increases in transporter number are paralleled by increases in levels of GLUT5 mRNA. In weaning rats, changes in sucrase activity are paralleled by changes in levels of sucrase mRNA (26). Finally, cortisol and other hormones are known to modulate the ontogenetic expression of sucraseisomaltase in the rat (12). Cortisol released by stress due to forced weaning can potentially induce fructose transport in our experimental rats. We have, however, shown that a NC or HG diet does not stimulate fructose transport, hence, induction by dietary fructose of fructose transport is specific. Nevertheless, it will be interesting to determine the effect of cortisol on ontogenetic expression of intestinal fructose transport.

Acknowledgments. The authors thank R. Vinnakota, D. Casirola, J. Shu, R. Hernandez (deceased, June 1993), and A. Taneja for help in experiments or for reviewing the manuscript.

\section{REFERENCES}

1. Romero R, Kleinman RE 1993 Feeding the very low birth weight infant. Pediatr Rev 14:123-132
2. Kien CL 1993 Carbohydrates. In: Tsang R, Lucas A, Uauy R, Zlotkin S (eds) Nutritional Needs of the Preterm Infant. Williams \& Wilkins, Baltimore, MD, pp 47-63

3. Lebenthal E, Lee PC, Heitlinger LA 1983 Impact of development of the gastrointestinal tract on infant feeding. J Pediatr 102:1-9

4. Bamford DR, Ingham PA 1975 Sugar absorption by fetal and neonatal rat intestine in vivo. J Physiol 248:335-348

5. Buddington RK, Diamond JM 1989 Ontogenetic development of intestinal nutrient transporters. Annu Rev Physiol 51:601-619

6. Toloza EM, Diamond JM 1992 Ontogenetic development of nutrient transporters in rat intestine. Am J Physiol 263:G593-G604

7. Karasov WH, Diamond JM 1987 Adaptation of intestinal nutrient transport. In: Johnson LR (ed) Physiology of the Gastrointestinal Tract, Ed. 2. Raven Press, New York, pp 1489-1497

8. Ferraris RP, Diamond JM 1989 Specific regulation of intestinal nutrient transporters by their dietary substrates. Annu Rev Physiol 51:125-141

9. Ferraris RP 1994 Regulation of nutrient transport. In: Johnson LR (ed) Physiology of the Gastrointestinal Tract, Ed. 3. Raven Press, New York, pp 1821-1844

10. Toloza EM, Diamond JM 1990 Ontogenetic development of transporter regulation in bullfrog intestine. Am J Physiol 258:G770-G773

11. Ferraris RP, Diamond JM 1993 Crypt/villus site of substrate-dependent regulation of mouse intestinal glucose transporters. Proc Natl Acad Sci USA 90:5868-5872

12. Henning SJ 1987 Functional development of the gastrointestinal tract. In: Johnson L (ed) Physiology of the Gastrointestinal Tract, Ed. 2. Raven Press, New York, pp 285-300

13. Ferraris RP, Vinnakota RR 1993 Regulation of intestinal nutrient transport is impaired in aged mice. J Nutr 123:502-511

14. Ferraris RP, Casirola DM, Vinnakota RR 1993 Dietary carbohydrate enhances intestinal sugar transport in diabetic mice. Diabetes 42:1579-1587

15. Diamond JM, Karasov WH 1984 Effect of dietary carbohydrate on monosaccharide uptake by mouse small intestine in vitro. J Physiol 349:419-440

16. Karasov WH, Diamond JM 1983 A simple method for measuring intestinal glucose transport in vitro. Am J Physiol 245:G445-G462

17. Burant CF, Saxena M 1994 Rapid reversible substrate regulation of fructose transporter expression in rat small intestine and kidney. Am J Physiol 267:G71-G79

18. Solberg DH, Diamond JM 1987 Comparison of different dietary sugars as inducers of intestinal sugar transporters. Am J Physiol 252:G574-G584

19. Altmann GG, Enesco M 1967 Cell number as a measure of distribution and renewal of epithelial cells in the small intestine of growing and adult rats. Am J Anat 121:319-336

20. Hediger MA, Coady MJ, Ikeda TS, Wright EM 1987 Expression cloning and cDNA sequencing of the $\mathrm{Na}^{+} /$glucose co-transporter. Nature 330:379-381

21. Cheeseman CI 1993 GLUT2 is the transporter for fructose across the rat intestinal basolateral membrane. Gastroenterology 105:1050-1056

22. Cheeseman CI, Maenz DD 1989 Rapid regulation of D-glucose transport in basolateral membrane in rat jejunum. Am J Physiol 256:G878-G883

23. Bode C, Eisenhardt JM, Haberich FJ, Bode JC 1981 Influence of feeding fructose on fructose and glucose absorption in rat jejunum and ileum. Res Exp Med 179:163-168

24. Scharrer E, Wolfram S, Raab W, Amann B, Agne N 1981 Adaptive changes of amino acid and sugar transport across the brushborder of rat jejunum. In: Robinson JWL, Dowling RH, Riecken E-O (eds) Mechanisms of Intestinal Adaptation. MTP Press, Lancaster, UK, pp 123-137

25. Mavrias DA, Meyer RJ 1973 Metabolism of fructose feeding on fructose transport and metabolism in the rat small intestine. Biochim Biophys Acta 291:531- 537

26. Nanthakumar NN, Henning SJ 1993 Ontogeny of sucrase-isomaltase gene expression in rat intestine: responsiveness to glucocorticoids. Am J Physiol 264:G306-G311 